\title{
Abstracts of the meeting of the Clinical Genetics Society held on 5 and 6 April 1984 at Salford University, Manchester
}

\begin{abstract}
Linkage studies of $X$ linked muscular dystrophy in the west of Scotland using four short arm X chromosome DNA polymorphisms

D E WILCOX, N A AFFARA, J R W YATES, I. KUNKEI, S A I.ATT, AND M A FERGiLSON-SMITH

Duncan Guthrie Institute of Medical Genetics, Yorkhill, Glasgow G.38SJ.
\end{abstract}

Twenty-four west of Scotland families with Duchenne and Becker muscular dystrophy have been studied using the short arm $\mathrm{X}$ chromosome probes R C8, L1.28, D2, and 99-6. Forty-seven obligate carriers from 84 families were heterozygous for DNA polymorphisms identified by these probes with the frequencies $4^{\circ}{ }_{0}, 55^{\circ}{ }_{0}, 68^{\circ}{ }_{0}$, and $43^{\circ}$ ", respectively. Recombination fractions have been calculated from fully phase known families as follows: DMD: L1.28 1/10; DMD: 996 0/9: DMD: D2 1/13. BMD: L1.28 3/8; BMD: 996 0/2: BMD: D2

2/12. D2: L1.28 4/17. Linkage studies were consistent with the BMD locus reing distal to L1.28 and proximal to D2, adding weight to the earlier suggestions that either BMD is allelic to or maps close to DMD.

\begin{abstract}
The use of DNA probes in carrier prediction for $\mathrm{X}$ linked muscular dystrophies

HYWFL WILLIAMS*, H $M$ KINC:SION*, 4 SARFARAZI*, BROWN*, N S T THOMAS*, K DAVITS', AND P S HARPER*

* Section of Medical Genetics, Welsh National School of Medicine, Heath Park, Carditf; and tDepartment of Biochemistry, St Mary's Hospital Medical School, London.
\end{abstract}

Information derived from two linked DNA protes ( $\mathrm{RC} 8$ and L 1.28) has been used to improve risk prediction for high risk female relatives of boys with $X$ linked muscular dystrophies. This information, especially when combined with $\mathrm{CK}$ data, significantly alters risk estimations previously calculated on the basis of pedigree information alone or combined with $\mathrm{CK}$. Many women given an intermediate risk can be re-allocated into either high or low risk categories. Confirmation of previous high or low risk estimates can also be achieved. One example is a daughter of an obligate carrier who had $50^{\circ} "$ risk for carrier status on pedigree information only, $11{ }^{\prime \prime}$ when $\mathrm{CK}$ information was added, and $2^{\circ} "$ " when DNA and $\mathrm{CK}$ results were combined. Data are currently available on 45 possible carriers of $X$ linked muscular dystrophies (21 Duchenne and 24 Becker). When the overall distribution of risks is analysed, the combined pedigree, DNA, and CK data are seen to give a considerably clearer separation into high and low risk groups than when only pedigree and $\mathrm{CK}$ data are used.

A cloned DNA sequence closely linked to haemophilia $A$ K HARPER*, R M WINTER $\dagger, M$ E PEMBREY*, D HARTLEY $\ddagger$, K F DAVIES,+ AND E G D TUDDENHAM $\$$

* Mothercare Unit of Paediatric Genetics, Institute of Child Health, London; †Clinical Research Centre, Northwick Park Hospital, Harrow, Middlesex; †St Mary’s Hospital Medical School, London; and \$Haemophilia Centre, Royal Free Hospital, London.

A singe copy sequence with the laboratory name DX13 (approved symbol DXS15), obtained from an X chromosome gene library and localised to Xq28 by the use of cell hybrids and in situ hybridisation, was used to search for restriction fragment length polymorphisms (RFLP). A Bgl II RFLP was found giving a 5.8 and or a $2.8 \mathrm{~kb}$ band (allele frequencies (). 5 and 0.5 ). Seventeen families with haemophilia A (0 to $11^{\circ}{ }_{0}$, factor VIII activity) were ascertained, and 11 of 21 obligate heterozygotes were heterozygous for the RFL.P. These double heterozygotes had 24 informative offspring and showed no crossovers between haemophilia $\mathrm{A}$ and DX13: maximum lod score $5.4^{\circ}$ " at recombination value of $0^{\circ}{ }^{\circ},\left(90^{\circ}{ }^{\circ}\right.$, confidence limits 0 to $9^{\circ}{ }_{0}: 95^{\circ}{ }_{0}$ confidence limits 0 to $12^{\circ}{ }_{0}$ ).

Study of the fragile $\mathrm{X}$ chromosome and mental retardation T P WEBB, S F BUNDFY, A THAKF, ANI) J TODD

Department of Clinical Genetics, Infant Development Unit, Birmingham Maternity. Hospital, Birmingham.

Boys were included in this study who were attending ESN(S) schools and were resident in Coventry, north and so:th Warwickshire, Rugby, or Walsall. All those whose records showed that they had a clear cause for their mental retardation were excluded. A detailed clinical examination was undertaken for each boy and a blood sample taken for cytogenetics. The culture conditions employed were those specifically designed to show the presence of the fragile $X$. Of the 156 boys so studied, 14 $\left(9^{\circ}, 1\right)$ were found to carry the $\mathrm{X}$ marker in between 4 and $32^{\prime \prime}$ " of their lymphocytes. Of 12 mothers, eight were certainly carriers and four index patients might have been new mutants. Of the obligate carriers in all 12 families, $30^{\circ}$ " could not be shown to carry the fragile $X$. Of 70 female relatives studied so far, 31 carried the fragile $X$, including all 10 who were mentally impaired. The marker $X$ was not found in any male relative of normal intelligence, although it was always detected in those who, were retarded. 
A premutation that generates the definitive mutation by recombination explains the inheritance of the Martin Bell syndrome (fragile $X$ )

M E PEMBREY*, R M WINTER $\dagger$, AND K E DAVIES +

* Mothercare Unit of Paediatric Genetics, Institute of Child

Health, London; †Clinical Research Centre, Northwick

Park Hospital, Harrow, Middlesex; and $\ddagger$ St Mary's Hospital Medical School, London.

The view that the Martin-Bell syndrome (X linked mental retardation with fragile site at $\mathrm{Xq} 27 / 8$ ) is inherited in a regular $\mathrm{X}$ linked fashion is becoming untenable with the increasing number of reports of transmission through phenotypically normal males. Analysis of the published pedigrees containing such males reveals that their heterozygous daughters are never mentally retarded, and have either no fragile site or very few indeed. By contrast, in the next generation, a third of the female heterozygotes are mentally subnormal with an average of $29^{\circ} \%$ fragile sites. The premutation (that does not cause mental retardation) has to be inherited and transmitted by a female tefore the Martin-Bell syndrome arises, almost certainly as a result of a recombination event. This hypothesis explains many of the puzzling features about the genetics of the Martin-Bell syndrome, but also complicates the interpretation of linkage analysis with genetic markers.

DNA probes useful in the study of Down's syndrome (i D STEWART, P HARRIS, J GALT, AND M A FERGUSON-SMITH Duncan Guthrie Institute of Medical Genetics, Yorkhill, Glasgow:

Seventeen recombinant phage containing human DNA were isolated from the chromosome 21 library of Krumlauf et al. Subsequent analysis showed that 13 of these contained unique sequence DNA and, by using the somatic cell hybrid THYB133R, five of these clearly mapped to chromosome 21. These probes and one obtained from R Krumlauf (D21 K9) have been regionally mapped on the chromosome using both chromosome sorting and a somatic cell hybrid. By using each of these probes against panels of genomic DNA samples digested with each of nine different restriction enzymes, two polymorphisms with a high rare allele frequency have been defined: one for $\mathrm{Bg} 111(0.46)$ and one for Msp $1(0.42)$. Both these probes and D21K9 which identifies a Taq 1 polymorphism have been used in family studies, some of which involve Down's syndrome children and their parents, to illustrate DNA dosage and to try to demonstrate the parental origin of the non-disjunction event.

Rearrangements of the C-myc gene in Burkitt's lymphoma S MALCOLM, M DAVIS, AND T H RABBITTS

MRC Human Genetic Diseases Research Group, Biochemistry Department, Queen Elizabeth College, London W8.

Specific chromosomal translocations have been found in Burkitt's lymphoma between chromosome $8 \mathrm{q} 24$ and either $14 q 32,2 p 12$, or $22 q 11$. It has been shown by molecular techniques that the translocation involves the $\mathrm{C}$-myc oncogene on $8 \mathrm{q} 24$ and one of the immunoglobulin loci, either heavy chain at $14 \mathrm{q} 32, \mathrm{~K}$ light chain at $2 \mathrm{p} 12$, or $\lambda$ light chain at 22q11. We have studied, using the technique of in situ hybridisation, the transiocation between chromosome 8 and chromosome 2 . We have shown that the variable kappa chain genes remain on the translocated chromosome 2 while the constant $\mathrm{K}$ genes are translocated to chrcmosome 8 . The $\mathrm{C}$-myc gene remains on chromosome 8 . This is in contrast to the situation in Daudi, an $8 ; 14$ type translocation, in which C-myc is translocated from 8 to 14. This shows that rearrangements can occur at either end of the C-myc gene in Burkitt's lymphoma. However, in each case the myc gene is located next to a constant region immunoglobin gene after translocation.

Quantitative analysis of the human karyotype by flow cytogenetics

P HARRIS, E BOYD, AND M A FERGUSON-SMITH

Duncan Guthrie Institute of Medical Genetics, Yorkhill, Glasgow.

The fluorescent activated cell sorter (FACS) has been used to measure the relative DNA content of human chromosomes. Normal persons show considerable variation in their flow karyotype profiles, due to chromosome polymorphisms, some of which are not readily seen by normal cytogenetic analysis. The extent of these variants can be accurately quantified by flow cytometry. Flow karyotype studies of several families have enabled the parental origin of many homologues to be identified including some from chromosomes not normally considered to be polymorphic. Further information about a person's karyotype can be produced using stains which preferentially bind to particular DNA base pairs. These stains produce different flow karyotype profiles due to the different proportions of AT and GC rich regions in human chromosomes. Information about the base composition of a particular chromosome can be obtained by comparing its position in flow karyotypes produced from the same person with different stains. This may enable some chromosome abnormalities of clinical significance to be distinguished from other changes.

Studies of British Huntington's chorea families with the polymorphic DNA probe $\mathbf{G} 8$

S YOUNGMAN*, D J SHAW*, J GUSELLA ${ }^{\dagger}$, AND P S HARPER* *Welsh National School of Medicine, Heath Park, Cardiff; and †Massachusetts General Hospital and Harvard Medical School, Boston, Massachusetts, USA.

The DNA probe $\mathrm{G} 8$ has been found to be closely linked to the locus for Huntington's chorea (HC) in two large American kindreds (Gusella et al, 1983). Preliminary studies in Great Britain have confirmed that the two polymorphic Hind III sites shown by G8 were present. The frequencies of the rare alleles in normal subjects $(n-45)$ were $0 \cdot 28$ and $0 \cdot 10$ for sites 1 and 2 respectively. In studies of unrelated patients affected with Huntington's chorea ( $n$. 34) the allele frequency was similar to that 
in the normal population. G8 also showed a third polymorphism with the restriction enzyme EcoRI, with an allele frequency of 0.5 for the presence of the site. Using the three polymorphic sites, approximately $75 \%$ of subjects will be informative. Selected large kindreds are under study for confirmation of genetic linkage. No unequivocal example of recombination has so far been detected in the seven kindreds studied.

Regional localisation of chromosome 19 markers and chromosomal localisation of ferritin genes

J D BROOK, D J SHAW, M WORWOOD, S J CRAGG, B M JONES, G A P BRUNS AND P S HARPER

Departments of Medical Genetics and Haematology, Welsh National School of Medicine, Heath Park, Cardiff; and Children's Hospital Medical Center, Boston, USA.

A panel of human/rodent somatic cell hybrids has been used to localise various markers to regions of chromosome 19 . The complement C3 gene maps to $19 \mathrm{p} 13 \rightarrow$ pter and glucose phosphate isomerase to $19 \mathrm{p} 13 \rightarrow \mathrm{q} 13$ in agreement with previous reports. The enzyme peptidase $D$ also maps to $19 p 13 \rightarrow q 13$, while the ferritin L-subunit gene maps to $19 q 13.2 \rightarrow$ qter. These results form the basis for constructing a physical map of chromosome 19 which can be aligned with the existing genetic linkage map. We can now order the chromosome 19 map as follows:

$$
\overline{\text { pter } F H C C_{3} \text { (GP1, Pep D, DM) FTL qter }} \text {. }
$$

This map can be used to assign the genes for myotonic dystrophy and other inherited diseases to specific chromosomal regions. We have also excluded the gene for the ferritin H-subunit from chromosome 19, the most likely localisation for this gene being chromosome 11 .

A new chromosome 19 polymorphic DNA sequence suitable for linkage studies in myotonic dystrophy

D J SHAW*, L MEREDITH*, J D BROOK*, K DAVIES $\dagger$, R WILLIAMSON $\dagger$, M SARFARAZI*, S HUSON*, AND P S HARPER* * Section of Medical Genetics, Welsh National School of Medicine, Heath Park, Cardiff; and †Department of Biochemistry, St Mary's Hospital Medical School, London.

We have isolated cloned sequences from a recombinant DNA library enriched for human chromosome 19. Unique sequence DNA fragments isolated from the clones were used to search for restriction fragment length polymorphisms (RFLPs) and were assigned to chromosomal regions using a somatic cell hybrid mapping panel. One DNA fragment, designated p1J2, showed an RFLP with the enzyme EcoR1, the heterozygote frequency being $0 \cdot 3$. The sequence mapped to the region $19 \mathrm{p} 13 \rightarrow \mathrm{q} 13$. Since this region also contains the enzyme peptidase $\mathrm{D}$, known to be closely linked to myotonic dystrophy, this should be a suitable RFLP for genetic linkage studies of myotonic dystrophy families.

The use of a microcomputer in the running of a general genetics clinic

P FARNDON AND L KERZIN-STORRAR

Department of Medical Genetics, St Mary's Hospital, Manchester.

A general genetic clinic has special administrative distinctions from a general medical clinic. These include organising the collection of pedigree and medical information before the consultation, requesting medical information on other members of the family, and reviewing results and families. Because of the large numbers of patients' case notes in current use, a microcomputer has been used to assist the organisation and running of the general genetic clinics in the Department of Medical Genetics at Manchester over the past 2 years. We use a commercially available menu-driven software programme which we have adapted for our use. The microcomputer has proved valuable and generates clinic lists, lists of patients waiting for visits and appointments, those waiting for further information about relatives or diagnoses, and patients for review. In addition, the system generates statistics on the diagnosis, specialty of referral, and health district of the patients seen, which may be useful in the planning of future services. The reasons for the setting up of the system and the advantages and disadvantages were discussed.

Spondyloepimetaphyseal dysplasia with joint laxity and severe progressive kyphoscoliosis

P BEIGHTON, G GERICKE, K KOZLOWSKI, G WALLIS, AND L GROBLER

MRC Unit for Inherited Skeletal Disorders, University of Cape Town Medical School, Observatory 7925, South Africa.

We have investigated 20 children with marked shortness of stature, gross joint laxity, and progressive kyphoscoliosis. Several died in their first decade and only two reached adulthood. Changes predominated in the vertebral bodies, epiphyses, and metaphyses and we have termed the condition spondyloepimetaphyseal dysplasia with joint laxity (SEMDJL). The major manifestations are the result of gross joint laxity. Congenital dislocation of the hips, talipes equinovarus, and dislocation of the radial heads may be present at birth. Kyphoscoliois develops at an early stage and usually progresses remorselessly, leading to cardiorespiratory embarrassment and spinal cord compression. Due to the inherent abnormality of connective tissues the results of operative stabilisation are poor. Several sets of affected sibs have been studied and it is evident that SEMDJL is inherited as an autosomal recessive trait. All were members of the Afrikaner community of South Africa and several have German ancestry. Carrier detection and antenatal diagnosis are not yet possible, but these problems are being approached by molecular genetic techniques. 
Genetic aspects of uncomplicated hydrocephalus

$\mathrm{K}$ M LAURENCE

Department of Child Health, Welsh National School of Medicine, Heath Park, Cardiff.

... Uncomplicated congenital hydrocephalus is found in 4 to 10 out of every 10000 births. In $30 \%$ it is due to aqueduct stenosis. The great majority of cases have a multifactorial aetiology but various family studies and the data from patients attending for genetic counselling in South Wales suggest that uncomplicated congenital hydrocephalus is not part of the neural tube defect spectrum of malformations. The risk to sibs of a child with congenital hydrocephalus is about 1 in 50 ( 1 in 40 for males, 1 in 80 for females). There is no obvious additional risk for neural tube defect. Probably less than $2 \%$ of uncomplicated hydrocephalus due to aqueduct stenosis has an X linked basis and such an aetiology should be suspected if the special clinical features are present, there is more than one male sib affected, or there are affected male relatives on the mother's side. Dandy-Walker syndrome may be recessively inherited and there are some other, but very rare, monogenic causes of hydrocephalus.

\section{Microphthalmos in a family}

I RUSSELL-EGiGiTT, A R FIELDER, M I LEVENE, AND I D YOUNG Departments of Ophthalmology and Child Health, Leicester Royal Infirmary, Leicester.

A large family is described in which at least 13 persons show or have shown ocular abnormalities, which include microphthalmos, strabismus, hypermetropia, short ocular axial length, and peripapillary disc pigmentation. In addition they tended to be of lower intelligence and to have a higher incidence of children with congenital abnormalities than unaffected sibs. Pedigree analysis is consistent with either autosomal or sex linked dominant inheritance. Careful examination of all family members indicated that penetrance was complete but expression very variable, with only subtle ocular abnormalities in some heterozygotes, while others showed unilateral or bilateral anophthalmos. No family member with normal eyes has had an affected child. All affected members showed involvement to some degree in both eyes. The risk of serious bilateral visual impairment in the offspring of an affected person is approximately 3 to $5 \%$.

\section{Hereditary spinocerebellar ataxia and genetic linkage with HLA \\ D KUMAR AND C E BLANK \\ Centre for Human Genetics, 117 Manchester Road, Sheffield.}

A linkage study was performed on five families to look for evidence of linkage for the gene of autosomal dominant spinocerebellar ataxia (SCA) with HLA locus within the MHC complex on chromosome 6 . Three families were informative for the linkage. The coded HLA haplotypes were used to calculate the likelihood as lod scores using the LIPED computer programme, assuming $90 \%$ penetrance and a population incidence of 1 per 100000 .
The total sum of lod scores from these five families does not support close linkage; however, a loose linkage could not be excluded. When the present results were pooled with previous reports, the total sum of lod scores for male and female recombination frequency $\left(\theta^{\mathrm{m}}\right)$ of 0.23 was significant in favour of linkage ( $\mathrm{z}$ : L4.195). The SCA gene appears to be located about 23 centimorgans from HLA locus. The symbol SCAI is proposed for a locus on the short arm of chromosome 6 loosely linked to HLA at which at least one allele produces a form of SCA (OPCA type 1 , Menzel type).

\section{Isomerism: a family study}

J BURN*, R COFFEY*, L ALLANं, M E PEMBREY*, P ROBINSON + , AND F J MACARTNEY $\ddagger$

* Mothercare Paediatric Genetics Unit, Institute of Child Health; †Paediatric Cardiology Unit, Guy's Hospital; and $¥$ Thoracic Unit, The Hospital for Sick Children, Great Ormond Street, London.

Isomerism (Ivemark syndrome, asplenia/polysplenia syndrome) involves abnormal symmetry, as shown in right isomerism by the typical features of bilateral right lungs, bronchi, and atria, and an absent spleen, and in left isomerism by two left 'sides' and multiple spleens. Reports of parental consanguinity and multiple affected sibs led to autosomal recessive designation, but the one previous family study found 60 probands with asplenia or polysplenia to have only three $\left(5^{\circ}\right)$ affected sibs. Major heart defects are common with isomerism. Using a consecutive series of 98 probands from the Thoracic Unit, first degree relatives were invited for study using ECG, echo, and 'Cincinnati' chest $x$-ray. None of the 64 parents examined showed abnormalities, but one mother had had surgery for a ventricular septal defect. Three couples, two Caucasian, were consanguineous. Among 107 sibs, one had right isomerism, a second died cyanosed at 9 days, and a third died of a 'hole in the heart' at one year. Among 63 asymptomatic sibs subjected to investigation, one girl, whose sister had right isomerism, had two left bronchi but a normal heart. Genetic analysis was presented.

A study of public awareness of genetic counselling services J M CONNOR, R S MACGREGOR, AND V INGLIS

Duncan Guthrie Institute of Medical Genetics, Glasgow, and Health Education Department, Greater Glasgow Health Board.

Questionnaires were completed by 891 persons who represented the following groups: final year medical students, final year student nurses, practising midwives and health visitors, social workers, school teachers, manual workers, non-manual workers, and professional employees. These groups were chosen as a cross-section of the general community and those from whom they might seek information about genetics. Final year medical students were fully a ware of the services available. Awareness was good among the midwives and health visitors, but was less than expected among the student nurses and school teachers. Among the general community fewer than 1 in 5 had any knowledge about genetic 
services. These results provide objective data to support the impression that genetic counselling services are currently underused, at least in part due to public ignorance.

Midtrimester amniocentesis: obstetric outcome and neonatal neurobehavioural status

JO-ANNE K FINEGAN, HELEN E HUGHES, B J QUARRINGTON, AND A DORAN

The Research Institute and Genetics Department, The Hospital for Sick Children; Department of Psychology, York University; Department of Obstetrics and Gynaecology, Toronto General Hospital, Toronto, Ontario.

The possible effects of midtrimester genetic amniocentesis on neurobehavioural status was studied in neonates of women who had had the procedure (n-100) and in neonates of women who declined the test $(n-56)$. Brazelton's Neonatal Behavioural Assessment Scale was administered to term neonates and did not reveal negative consequences of amniocentesis on neonatal orientationinteraction, motor coordination, state control, and physiological response to stress. Information on obstetric complications was also collected and presented by the descriptive case method. The findings raise questions regarding the temporal relaticnship between amniocentesis and fetal loss and focus attention on preterm birth as a potential risk that has not yet been investigated in detail. This study provides the foundation for our prospective longitudinal follow-up, in which the cohort will be reassessed later in infancy and in childhood. 